\title{
Effects of various arterial infusion solutions on red blood cells in the newborn
}

\author{
Jodi K Jackson, Douglas P Derleth
}

\begin{abstract}
Aim-To examine in vitro the effects of brief contact with various infusion solutions on red blood cells from newborn infants, as occurs in the "waste" syringe during routine blood sampling from umbilical artery catheters. The mixture of blood and solution in the "waste" syringe is usually reinfused into the baby. Reinfused red blood cells may be damaged by the infusion solution. It is hypothesised that an isotonic amino acid solution would cause no red blood cell agglutination and no more haemolysis than many commonly used solutions.
\end{abstract}

Methods-Blood was obtained from the placentas of 15 normal term babies. Haemolysis was estimated by measuring plasma (free) haemoglobin after mock blood sampling. Agglutination was measured semiquantitatively by direct observation.

Results-A $0.25 \%$ normal saline solution caused $5.4 \%$ haemolysis, significantly more than all the other fluids tested. There was less haemolysis with $0.25 \%$ normal saline when there was complete mixing of blood and solution within the "waste" syringe. Normal saline and isotonic sodium acetate solutions caused $<0.1 \%$ haemolysis, significantly less than all the other fluids tested. The isotonic amino acid solution caused $0.8 \%$ haemolysis, which is similar to that caused by the remaining solutions tested. Agglutination was seen with isotonic dextrose and with the two isotonic amino acid solutions containing cysteine.

Conclusions-Isotonic amino acid solution (without added cysteine) caused no agglutination and the same or less haemolysis than many commonly used solutions and may offer advantages in nutrition and fluid balance.

(Arch Dis Child Fetal Neonatal Ed 2000;83:F130-F134)

Keywords: haemolysis; agglutination; umbilical artery catheter; infusion solutions; amino acids; nutrition

Department of

Pediatric and

Adolescent Medicine, Mayo Clinic,

Rochester, MN 55905,

USA

J K Jackson

D P Derleth

Correspondence to:

Dr Derleth, Mayo Clinic

Ei-S22, Rochester, MN

55905, USA

email:

derleth.douglas@mayo.edu

Accepted 27 March 2000 and solution in it is usually not wasted, but reinfused into the baby. The reinfused blood may contain red blood cells that have been damaged by haemolysis or agglutination by contact with the infusion solution.

Various arterial infusion solutions are used with little scientific data to support their safety or benefit. ${ }^{12}$ Despite the widespread use of umbilical artery catheters for blood sampling, no study has yet examined the damage to newborn red blood cells resulting from the brief mixing of newborn blood with commonly used arterial infusion solutions.

Normal saline (NS) is the solution least likely to injure red blood cells. However, significant sodium intake in the first days of life has been associated with hypernatraemia and an increased incidence of bronchopulmonary dysplasia. $^{34}$

Isotonic dextrose (D5W) may be used instead of saline, but dextrose in the solution may contribute to hyperglycaemia and may also affect blood sugar determinations in blood samples drawn from the arterial line. In addition, D5W causes macroscopic agglutination of adult red blood cells. ${ }^{5}{ }^{6}$ This agglutination is reversible with the addition of salt, but there is irreversible damage to the red blood cells, which leads to their premature haemolysis in vivo after reinfusion. ${ }^{6-8}$ Premature haemolysis (without agglutination) also occurs when adult red blood cells come into contact with solutions of dextrose and various salt concentrations and this is due to a direct effect of the dextrose on the red blood cells. ${ }^{8-10}$

In view of these facts, hypotonic saline is often selected as the arterial infusion solution because it does not contain sugar and it minimises sodium intake. However, adult red blood cells haemolyse when mixed with hypotonic saline solutions. ${ }^{11-13}$ This haemolysis is worsened by increased contact time with the solution and with increasing ratio of solution to blood. ${ }^{11-13}$

These problems could be avoided by infusing an isotonic amino acid (IAA) solution through the umbilical artery catheter. Indeed, the early delivery of up to $2.5 \mathrm{~g}$ amino acids $/ \mathrm{kg} /$ day appears to be biochemically safe and has been shown to improve protein balance, ${ }^{14-21}$ minimising the loss of as much as $3 \%$ of total body protein a day. ${ }^{15}$ Also, babies receiving amino acids tolerate more exogenous glucose, and therefore energy intake can be increased in the first days of life. ${ }^{14}$

We examined in vitro the haemolysis and agglutination that occurs on contact between blood and various arterial infusion solutions by simulating the interaction that takes place in the waste syringe on an umbilical artery 


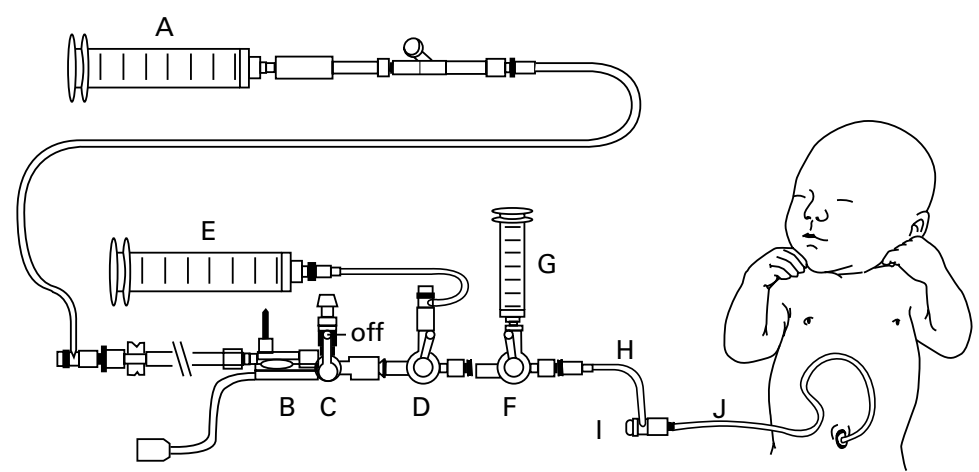

Figure 1 Apparatus used for infusion of maintenance solution and sampling of blood through an umbilical arterial catheter in sick newborn infants. A, Maintenance solution attached to a pump, delivering at a constant rate; $B$, transducer; $C$, stopcock for zeroing transducer; $D$, stopcock attached to flush solution; $E$, flush solution syringe; $F$, stopcock attached to "waste" syringe; $G$, waste syringe; $H$, T-connector; I, draw port; $\mathcal{F}$, umbilical arterial catheter. Usually maintenance solution is pumped through this apparatus through the umbilical artery catheter into the baby at a constant rate.

catheter. We hypothesised that an IAA solution would cause no red blood cell agglutination and no more haemolysis than many commonly used infusion solutions.

\section{Methods}

This study was approved by the institutional review board of the Mayo Clinic.

SAMPLE COLLECTION

Newborn blood was collected and immediately heparinised ( 3 units $/ \mathrm{ml}$ ) from 15 placentas over a seven day period. All placentas were from term infants with no known illness or anomalies. No samples were stored for more than one hour.

\section{MOCK BLOOD SAMPLING}

Mock blood sampling was performed to simulate the brief mixing that takes place in the waste syringe when blood is sampled and waste blood reinfused into a newborn using the umbilical artery catheter apparatus used in our nursery (fig 1). ${ }^{22}$ The placental blood was drawn through a similar apparatus to simulate the drawing and reinfusing of "waste" blood into a baby (fig 2). The tubing of this apparatus was first filled with $0.9 \mathrm{ml}$ of the designated solution. The end of the catheter was then placed into the heparinised placental blood. The waste syringe was used to draw back the solution within the tubing, followed by placental blood until the waste syringe contained 2.5 $\mathrm{ml}$. The arterial catheter was then removed from the receptacle of placental blood and the

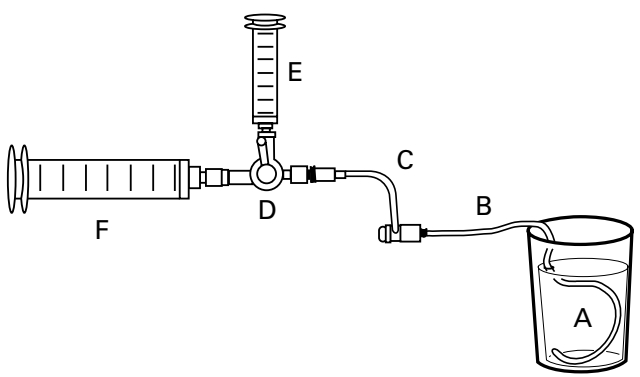

Figure 2 Apparatus for "mock draw". A, Receptacle of heparinised placental blood; $B$, umbilical arterial catheter; $C$, T-connector; D, stopcock; $E$, waste syringe; $F$, flush syringe. solution/blood mixture in the waste syringe and tubing was "reinfused" into a test tube (rather than into a baby as with clinical blood sampling). The tubing was then flushed with $0.5 \mathrm{ml}$ of the same solution into the same test tube. Air was then infused to ensure complete emptying of the tubing.

The drawing up and reinfusing was performed over 60 seconds in most draws, and over three minutes in draws designated as "drawn up slowly". The mixing between the solution and the blood was kept to a minimum during most draws by keeping the solution layered above the blood within the waste syringe, but there was intentional mixing during the draws designated as "mixed completely."

As it is known that time is a factor in the interaction of solutions with blood, ${ }^{11-13}$ any haemolysis or indirect effect of the solution on the blood was quenched by an appropriate amount of hypertonic saline to make the resulting mixture isonatraemic immediately on entering the collection test tube. This quenching simulated the normalisation of solution tonicity that occurs when waste blood is reinfused into a newborn infant. In preliminary work on this method, the quenching was shown to stop any haemolysis.

The above procedure was performed with each of the following solutions: NS; $0.25 \% \mathrm{NS}$; IAA solution (described below); D5W; $0.5 \%$ NS; IAA + cysteine (L-cysteine USP; American Regent Laboratories, Shirley, New York, USA); isotonic $(154 \mathrm{mEq} / \mathrm{l})$ sodium acetate; total parenteral nutrition (TPN) + lipids; IAA + cysteine + trace minerals (Pedtrace-4; Fujisawa USA, Deerfield, Illinois, USA) and vitamins (MVI Pediatric; Catalytica Pharmaceuticals, Greenville, North Carolina, USA); 5\% dextrose in $0.25 \% \mathrm{NS}$ (D5 $0.25 \% \mathrm{NS}$ ); $0.25 \% \mathrm{NS}$ drawn up slowly; $0.25 \%$ NS mixed completely; $0.25 \%$ NS drawn up slowly and mixed completely. The order in which the solutions were tested was randomised.

The IAA solution $(312 \mathrm{mOsm} / \mathrm{l})$ was made by diluting $10 \%$ Trophamine (Braun Medical, Irvine, California, USA) 1:1.8 with water.

\section{HAEMOLYSIS MEASUREMENTS}

Although various combinations of test solutions were used with blood from each individual placenta, NS was used with blood from all 15 placentas as an internal standard, controlling for the amount of baseline haemolysis occurring as a function of time.

The plasma (free) haemoglobin concentration was measured for each test tube sample. ${ }^{23}$ Those measuring this value were blinded to the test solution. A complete blood count was performed on blood from each of the 15 placentas to provide the whole blood haemoglobin concentrations and packed cell volumes needed to make the haemolysis calculations. ${ }^{2425}$

We calculated the amount of plasma free haemoglobin that would be present if all of the red blood cells in the $2.5 \mathrm{ml}$ waste blood were haemolysed, and compared this value with the amount of plasma haemoglobin actually measured. The "plasma" contributed by the haemolysed red blood cells was small, and 
Table 1 Macroscopic agglutination

\begin{tabular}{lllllllll}
\hline Sample & NS & D5W & $0.5 \% N S$ & IAA & $\begin{array}{l}\text { IAA+ } \\
\text { cysteine }\end{array}$ & $\begin{array}{l}\text { Isotonic sodium } \\
\text { acetate }\end{array}$ & TPN & $\begin{array}{l}\text { IAA + cysteine }+ \text { D } \\
\text { minerals and vitamins }\end{array}$ \\
\hline $\mathrm{H}$ & - & $2+$ & - & - & $3+$ & - & - & $1+25 \%$ \\
NS
\end{tabular}

One drop of sample whole blood was mixed with $4 \mathrm{ml}$ test solution, and the amount of macroscopic agglutination recorded; large clumps are classified as $4+$, smooth appearance is classified as - , with $+/-, 1+, 2+, 3+$ being intermediate. ${ }^{911}$

NS, normal saline; D5W, isotonic dextrose; IAA, isotonic amino acids; TPN, total parenteral nutrition; D5 $0.25 \% \mathrm{NS}, 5 \%$ dextrose in $0.25 \%$ normal saline.

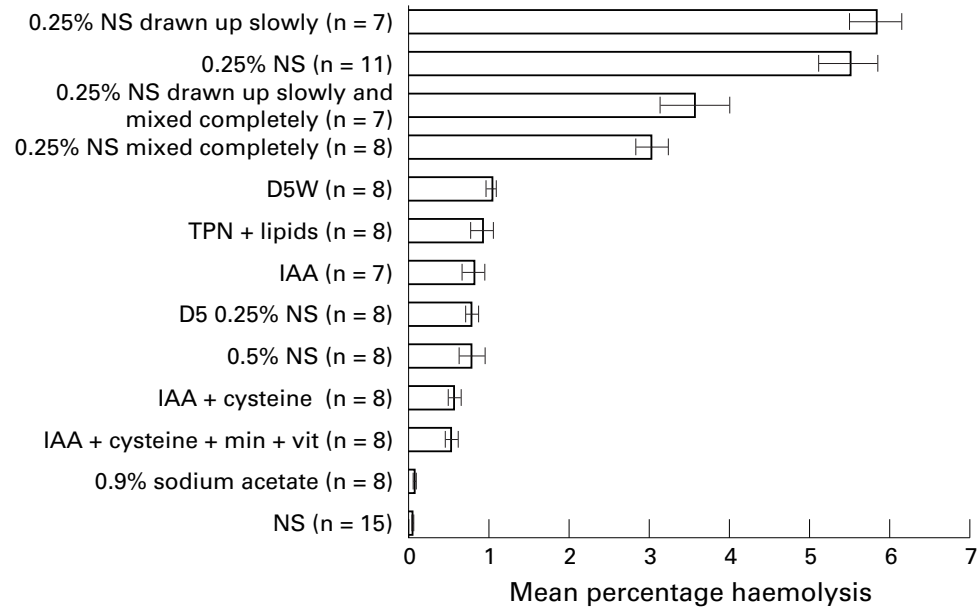

Figure 3 Comparison of mean haemolysis with each solution. NS, Normal saline; D5W, isotonic dextrose; TPN, total parenteral nutrition; IAA, isotonic amino acids; D5 $0.25 \%$ NS, $5 \%$ dextrose in $0.25 \%$ normal saline; min, minerals; vit, vitamins; 0.9 sodium acetate, isotonic sodium acetate. The mean haemolysis and standard error for each solution, based on the total number of samples used, are statistically compared by a two sample t test. All values are means with bars representing standard error. Percentage haemolysis in this two sample comparison is statistically higher for the $0.25 \%$ NS group $(p<0.001)$ than for all the other groups, apart from $0.25 \%$ NS drawn up slowly $(p=0.227)$. Percentage

haemolysis is less for the NS group $(p<0.001)$ than for all for the other groups, apart from the isotonic sodium acetate group $(p=0.466)$.

therefore not factored into the calculations. The amount of haemolysis is reported as the percentage of red blood cells in the waste syringe that haemolysed.

\section{AGGLUTINATION MEASUREMENTS}

Agglutination was evaluated by adding one drop of blood to $4 \mathrm{ml}$ test solution. At this ratio of solution to blood, one can easily appreciate the amount of macroscopic agglutination taking place. ${ }^{68}$ This concentration also approximates the mixing that takes place near the interface of the blood and test solution. The same two blinded experimenters independently classified each sample on a semiquantitative scale of 0 to $4+$ agglutination.
STATISTICAL ANALYSIS

The amount of haemolysis caused by various solutions was evaluated in comparison with that caused by NS, $0.25 \% \mathrm{NS}$, and the IAA solution. The amount of haemolysis caused by $0.25 \%$ NS with blood/solution contact for 60 seconds and minimised mixing was also compared with slower sampling and/or complete mixing with the same solution.

Test solutions were compared using the paired $t$ test, thereby using each placenta sample as its own control. As not all test solutions were run on every sample, the paired analyses were based on a variable number of paired samples (generally four to eight). The pairwise differences were also evaluated by unpaired methods-for example, two sample $t$ test and Wilcoxon rank sum test. However, as the unpaired analyses reached similar levels of significance, only the data of the paired analyses are reported. Haemolysis percentages are reported as mean (SEM). All calculated $\mathrm{p}$ values are two sided and not adjusted for multiple comparisons.

\section{Results}

D5W and the IAA solutions containing cysteine caused obvious macroscopic agglutination (table 1 ). The other solutions caused no agglutination.

Figure 3 shows the amount of haemolysis with each of the test solutions.

Haemolysis was significantly lower with NS than with all the other solutions tested (all $\mathrm{p}<0.001$ ) except isotonic sodium acetate, which was similar to NS (table 2).

Haemolysis was significantly higher with $0.25 \%$ NS than with all the other solutions tested (all p < 0.004; table 3).

Haemolysis was not significantly different with the IAA solution than with D5W, $0.5 \%$ NS, D5 $0.25 \%$ NS, IAA + cysteine, TPN +

Table 2 Haemolysis in test solutions compared with normal saline

\begin{tabular}{|c|c|c|c|c|c|}
\hline \multirow[b]{2}{*}{ Solution tested } & \multirow{2}{*}{$\begin{array}{l}\text { No of } \\
\text { patients }\end{array}$} & \multicolumn{2}{|l|}{ Haemolysis (\%) } & \multirow{2}{*}{$\begin{array}{l}\text { Difference in \% } \\
\text { haemolysis, comparison } \\
\text { solution — normal saline }\end{array}$} & \multirow{2}{*}{$\begin{array}{l}\text { Paired t test (2 } \\
\text { sided } p \text { value })^{*}\end{array}$} \\
\hline & & Solution tested & Normal saline & & \\
\hline $0.25 \% \mathrm{NS}$ & 11 & $5.434(0.372)$ & $0.070(0.016)$ & $5.364(0.363)$ & $<0.001$ \\
\hline IAA & 7 & $0.819(0.124)$ & $0.093(0.022)$ & $0.726(0.130)$ & 0.001 \\
\hline D5W & 8 & $1.029(0.059)$ & $0.080(0.020)$ & $0.949(0.055)$ & $<0.001$ \\
\hline $0.5 \% \mathrm{NS}$ & 8 & $0.796(0.154)$ & $0.089(0.019)$ & $0.707(0.138)$ & 0.001 \\
\hline IAA + cysteine & 8 & $0.570(0.068)$ & $0.089(0.019)$ & $0.481(0.052)$ & $<0.001$ \\
\hline Isotonic sodium acetate & 8 & $0.089(0.021)$ & $0.089(0.019)$ & $0(0.004)$ & 0.967 \\
\hline TPN + lipids & 8 & $0.922(0.137)$ & $0.089(0.019)$ & $0.833(0.138)$ & $<0.001$ \\
\hline IAA + cysteine + minerals + vitamins & 8 & $0.534(0.078)$ & $0.089(0.019)$ & $0.445(0.064)$ & $<0.001$ \\
\hline D5 $0.25 \%$ NS & 8 & $0.801(0.077)$ & $0.089(0.019)$ & $0.712(0.060)$ & $<0.001$ \\
\hline
\end{tabular}

Values are expressed as mean (SEM).

*For the paired $t$ test, the analysis was based on the paired differences and only patients who had both sets of measurements contributed to the analysis.

NS, normal saline; D5W, isotonic dextrose; IAA, isotonic amino acids; TPN, total parenteral nutrition; D5 $0.25 \% \mathrm{NS}, 5 \%$ dextrose in $0.25 \%$ normal saline. 
Table 3 Haemolysis in test solutions compared with $0.25 \%$ normal saline

\begin{tabular}{|c|c|c|c|c|c|}
\hline \multirow[b]{2}{*}{ Solution tested } & \multirow[b]{2}{*}{$\begin{array}{l}\text { No of } \\
\text { patients }\end{array}$} & \multicolumn{2}{|l|}{ Haemolysis (\%) } & \multirow{2}{*}{$\begin{array}{l}\text { Difference in } \% \\
\text { haemolysis, } 0.25 \% \\
\text { NS-comparison } \\
\text { solution }\end{array}$} & \multirow[b]{2}{*}{$\begin{array}{l}\text { Paired } t \text { test } \\
(2 \text { sided } p \text { value })^{*}\end{array}$} \\
\hline & & $0.25 \% \mathrm{NS}$ & Solution tested & & \\
\hline NS & 11 & $5.434(0.372)$ & $0.070(0.016)$ & $5.364(0.363)$ & $<0.001$ \\
\hline IAA & 4 & $5.967(0.476)$ & $0.889(0.142)$ & $5.078(0.605)$ & 0.004 \\
\hline $\mathrm{D} 5 \mathrm{~W}$ & 8 & $5.500(0.503)$ & $1.029(0.059)$ & $4.471(0.462)$ & $<0.001$ \\
\hline $0.5 \% \mathrm{NS}$ & 4 & $5.967(0.476)$ & $0.888(0.322)$ & $5.079(0.292)$ & $<0.001$ \\
\hline IAA + cysteine & 4 & $5.967(0.476)$ & $0.655(0.125)$ & $5.312(0.375)$ & 0.001 \\
\hline Isotonic sodium acetate & 4 & $5.967(0.476)$ & $0.105(0.039)$ & $5.862(0.439)$ & 0.001 \\
\hline TPN + lipids & 4 & $5.967(0.476)$ & $1.157(0.208)$ & $4.81(0.549)$ & 0.003 \\
\hline IAA + cysteine + minerals + vitamins & 4 & $5.967(0.476)$ & $0.621(0.130)$ & $5.346(0.377)$ & 0.001 \\
\hline D5 $0.25 \% \mathrm{NS}$ & 4 & $5.967(0.476)$ & $0.856(0.158)$ & $5.111(0.321)$ & 0.001 \\
\hline $0.25 \%$ NS drawn up slowly & 7 & $5.129(0.506)$ & $5.774(0.331)$ & $-0.645(0.480)$ & 0.227 \\
\hline $0.25 \%$ NS mixed completely & 7 & $5.423(0.441)$ & $3.052(0.232)$ & $2.371(0.247)$ & $<0.001$ \\
\hline $0.25 \%$ NS drawn up slowly and mixed completely & 7 & $5.129(0.506)$ & $3.532(0.431)$ & $1.597(0.266)$ & 0.001 \\
\hline
\end{tabular}

Values are expressed as mean (SEM).

*For the paired $t$ test, the analysis was based on the paired differences and only patients who had both sets of measurements contributed to the analysis.

NS, normal saline; D5W, isotonic dextrose; IAA, isotonic amino acids; TPN, total parenteral nutrition; D5 0.25\% NS, $5 \%$ dextrose in $0.25 \%$ normal saline.

lipids, or IAA + cysteine + minerals and vitamins. With an effective sample size of seven, these comparisons had a $61 \%$ chance of detecting a difference of at least one standard deviation between the paired group means.

The rate at which the $0.25 \%$ NS solution was drawn up did not make a significant difference to the amount of haemolysis that occurred ( $p=0.227$; fig 3 ). However, complete mixing of this solution with the blood (rather than keeping the two fluids separate in the waste syringe) significantly decreased haemolysis $(\mathrm{p}<0.001$; fig 3).

\section{Discussion}

A significant increase in haemolysis occurred when $0.25 \%$ NS was used as the test solution in comparison with all the other solutions tested. The haemolysis was about seven times that occurring with the IAA solutions and 67 times that occurring with NS. At the very least, these results suggest that sodium should be added to a hypotonic saline infusion solution when more sodium is needed, rather than to the venous fluids, to minimise haemolysis.

Based on the average blood haemoglobin concentration $(15 \mathrm{~g} / \mathrm{dl})$ found in these placental blood samples and 10 blood draws a day, about $3.75 \mathrm{~g}$ haemoglobin a day would be exposed to the solution in the umbilical artery catheter. At the $5.4 \%$ haemolysis rate seen with $0.25 \% \mathrm{NS}$, this could result in a loss of $203 \mathrm{mg}$ haemoglobin a day in addition to the $135 \mathrm{mg}$ a day lost as the result of normal red blood cell destruction (assuming a red blood cell lifespan of 60 days in a $600 \mathrm{~g}$ baby). By a similar calculation, only an additional $3 \mathrm{mg}$ haemoglobin would be lost each day if NS or isotonic sodium acetate were used, and $30 \mathrm{mg}$ if an IAA solution were used.

The breakdown of $1 \mathrm{mg}$ haemoglobin generates $0.036 \mathrm{mg}$ bilirubin. Therefore the $135 \mathrm{mg}$ haemoglobin lost daily as the result of normal red blood cell destruction must generate 4.9 mg bilirubin a day. As this represents only $80 \%$ of total bilirubin production, the total physiological production of bilirubin would be 6.1 $\mathrm{mg}$ a day. The haemolysis caused by the $0.25 \%$ NS would therefore generate an additional 7.3 mg bilirubin a day, more than doubling the physiological bilirubin production. This increased bilirubin could put a small premature newborn at greater risk because of its toxic effects or greater exposure to phototherapy. By similar calculations, the IAA solution and most of the other fluids would generate an additional $1.0 \mathrm{mg}$ bilirubin a day, and NS and isotonic sodium acetate would generate about $0.1 \mathrm{mg}$ bilirubin a day.

How this increase in bilirubin production would affect serum bilirubin concentration is difficult to estimate. The plasma disappearance curves for unconjugated bilirubin have been defined and analysed in adults in terms of three exponentials. ${ }^{26}$ Extrapolation of this information to the sick newborn is difficult and imprecise. The effect of increased serum bilirubin may be amplified by the weak binding of bilirubin to serum albumin in the newborn, resulting in a relative excess of free bilirubin in the presence of a bilirubin conjugating mechanism that is probably saturated..$^{27-29}$

Additional unfavourable outcomes could result from increased haemolysis. This increase in haemolysis may lead to increased free iron and therefore increase injury due to oxygen free radicals. ${ }^{30}$ Additional plasma haemoglobin may also bind nitric oxide, blocking its vasodilatory effects. ${ }^{31} 32$

Although we did see agglutination when we used the D5W and IAA solutions containing cysteine, the amount of in vitro haemolysis caused by these solutions was not particularly increased. Although such agglutination is reversible, irreversible damage to the red blood cells leads to a greatly shortened life span in vivo. ${ }^{6-8}$ This premature red blood cell destruction is presumably the result of an in vivo process that cannot be shown in vitro.

We assumed that keeping the solution and blood layered separately in the waste syringe would decrease haemolysis. We were surprised to find that complete mixing of $0.25 \%$ NS with blood actually decreased haemolysis. It may therefore be better for all of the red blood cells to be exposed to a less hypotonic mixture of $0.25 \%$ NS and plasma than for a smaller number of red blood cells to be exposed to pure $0.25 \%$ NS.

A venous catheter is typically used to provide for most of the varying water, sugar, pressor, 
and other needs of the sick premature infant. The addition of amino acids to the fluids in the venous catheter may be logistically difficult. However, the use of amino acids in the umbilical artery catheter would be simple, would contribute no sugar and virtually no sodium, and would supply useful nutrition. The amino acid infusion in the umbilical artery catheter would not be affected by clinically necessary variations in the delivery of the other fluids in the venous lines. IAA solution, if given at 1 $\mathrm{ml} / \mathrm{h}$ in the umbilical artery catheter, would deliver $0.86 \mathrm{~g}$ amino acids a day. For the weight range $0.5-1.5 \mathrm{~kg}$, the amount received would be $0.57-1.7 \mathrm{~g} / \mathrm{kg} / \mathrm{day}$, a range that is probably both safe and beneficial. ${ }^{14-17}{ }^{19-21}$

This study looked at the interaction of the blood and infusion solution in the waste syringe using the sampling procedure practiced in our nursery. Other methods of drawing up waste blood and other ratios of blood/fluid volumes would presumably show different amounts of haemolysis. The study is also limited to only some of the many possible infusion solutions.

One problem with the use of the IAA solution not investigated here is the effect of the small bolus of amino acids that would occur with each blood sampling event. This could be lessened by using a $0.5 \%$ NS solution to flush the tubing after the reinfusion of the contents of the waste syringe. With ten blood draws a day, this would only amount to an additional $0.4 \mathrm{mEq}$ sodium a day.

\section{CONCLUSION}

This study simulated the drawing back and reinfusion of waste blood through an umbilical artery catheter in vitro. We showed significantly more haemolysis with $0.25 \%$ NS than with all the other test solutions. This is new information to consider when choosing an infusion solution.

An IAA solution (without cysteine) caused less haemolysis and no agglutination. Infusing the IAA solution through the umbilical artery catheter leaves the venous catheter available to carry the dextrose, pressors, and other fluids that fluctuate in rate over the first few days of life depending on patient needs. In addition to improving protein balance and increasing glucose tolerance, the IAA solution has the advantage over NS or isotonic sodium acetate of contributing almost no sodium to the hypernatraemia recognised as a common complication in the first days of life.

This study suggests that an IAA solution is as safe as or safer than many commonly used arterial infusion solutions. Further in vivo research is necessary to investigate the effects of using an IAA solution on red blood cell haemolysis and nutrition.

We thank Rosemary Horsman, RN, for assistance in data We thank Rosemary Horsman, RN, for assistance in data
collection and nursing expertise and Terry Ryan, RN, for help in collection and nursing expertise and Terry Ryan, RN, for help in generating illustrations. We thank the members of the Pediatric
Pharmacy for their help in generating test solutions. We also Pharmacy for their help in generating test solutions. We also thank Regina Scheidt and the Metabolic Hematology Labora-
tory, as well as Breanndan Moore, MD, Rebecca Reisner, and tory, as well as Breanndan Moore, MD, Rebecca Reisner, and
Leslie Hampton in Transfusion Medicine for their expertise and Leslie Hampton in Transfusion Medicine for their expertise and the use of their laboratory facilities. We would like to thank Amy Weaver in the Department of Biostatistics for her help and guidance in the statistical analysis of our results. We also thank
Stuart Jackson, PhD, for his support and computer software expertise. All financial support was obtained through the Mayo
Foundation Clinical Research Funding Program.

1 Fletcher MA, Brown DR, Landers S, Seguin J. Umbilical arterial catheter use: report of an audit conducted by the study group for complications of perinatal care. Am f Perinatol 1994;11:94-9.

2 Hodding JH. Medication administration via the umbilical arterial catheter: a survey of standard practices and review of the literature. Am f Perinatol 1990;7:329-32.

3 Costarino AT Jr, Gruskay JA, Corcoran L, Polin RA, Baumgart S. Sodium restriction versus daily maintenance replacement in very low birth weight premature neonates: a randomized, blind therapeutic trial. $f$ Pediatr 1992;120:99-106.

4 Lorenz JM, Kleinman LI, Ahmed G, Markarian K. Phases of fluid and electrolyte homeostasis in the extremely low birth weight infant. Pediatrics 1995;96:484-9.

5 Strautz RL, Nelson JM, Meyer EA, Shulman IA. Compatibility of ADSOL-stored red cells with intravenous ibility of ADSOL-stored red cells with
solutions. Am f Emerg Med 1989;7:162-4.

6 Jones JH, Kilpatric GS, Fanks EH. Red cell aggregation in dextrose solution. F Clin Pathol 1962;15:161-2.

7 Weisz-Carrington P. Incompatible intravenous fluids: their potential effect on blood and blood transfusion. Immunohematology 1988;31:1-5.

8 Ryden SE, Oberman HA. Compatibility of common intravenous solutions with CPD blood. Transfusion 1975;15:250-5.

9 DeCesare WR, Bove JR, Ebaugh FG. The mechanism of the effect of iso- and hyperosmolar dextrose-saline solutions on in vivo survival of human erythrocytes. Transfusion 1964;4:237-50.

10 Easton DJ, Ternoey CM. Hemolysis of donor red cells in "two thirds-one third" solution. Transfusion 1985; 25:85.

11 Krzyzaniak JF, Alvarez Nunez FA, Raymond DM, Krzyzaniak JF, Alvarez Nunez FA, Raymond DM,
Yalkowsky SH. Lysis of human red blood cells. 4. Comparison of in vitro and in vivo hemolysis data. $f$ Pharm Sci 1997;86:1215-17.

12 Krzyzaniak JF, Raymond DM, Yalkowsky SH. Lysis of human red blood cells. 1 . Effect of contact time on water induced hemolysis. PDA f Pharm Sci Technol 1996;50:223-6.

13 Whitelaw JP. Hemolysis caused by half-physiologic-strength saline. Transfusion 1990;30:78.

14 Rivera A Jr, Bell EF, Bier DM. Effect of intravenous amino acids on protein metabolism of preterm infants during the first three days of life. Pediatr Res 1993;33:106-11.

15 Rivera A Jr, Bell EF, Stegink LD, Ziegler EE. Plasma amino acid profiles during the first three days of life in infants with respiratory distress syndrome: effect of parenteral with respiratory distress syndrome: effect of parenteral

16 Murdock N, Crighton A, Nelson LM, Forsyth JS. Low birthweight infants and total parenteral nutrition immediately after birth. II. Randomized study of biochemical tolerance of intravenous glucose, amino acids, and lipid. Arch Dis Child Fetal Neonatal Ed 1995;73:F8-12.

17 Anderson TL, Muttart CR, Bieber MA, Nicholson JF, Heird WC. A controlled trial of glucose versus glucose and amino acids in premature infants. $\mathcal{F}$ Pediatr 1979;94:947-51.

18 Hammerman C, Aramburo MJ. Decreased lipid intake reduces morbidity in sick premature neonates. $\mathcal{F}$ Pediatr 1988;113:1083-8.

19 Saini J, MacMahon P, Morgan JB, Kovar IZ. Early parenteral feeding of amino acids. Arch Dis Child 1989;64:1362-6.

20 Rubecz I, Mestyan J, Varga P, Klujber L. Energy metabolism, substrate utilization and nitrogen balance in parenterally fed postoperative neonates and infants. The effect of glucose, glucose + amino acids, lipid + amino acids infused in isocaloric amounts. F Pediatr 1981;98:42-6.

21 Berry MA, Abrahamowicz M, Usher RH. Factors associated with growth of extremely premature infants during initial hospitalization. Pediatrics 1997;100:640-6.

22 Derleth DP. A cleaner blood sampling apparatus. Neonatal Network 1997;16:78-9.

23 Fairbanks VF, Ziesmer SC, O'Brien PC. Methods for measuring plasma hemoglobin in micromolar concentration compared. Clin Chem 1992;38:132-40.

24 Coulter Corporation. Coulter hematology. St Louis, MO: Coulter STKS, 1992 .

25 Coulter WH. High speed automatic blood cell counter and cell size analyzer. Proceedings of the National Electronics Conference 1956;12:1034.

26 Berk PD, Howe RB, Bloomer JR, Berlin NI. Studies of bilirubin kinetics in normal adults. $\mathcal{F}$ Clin Invest 1969;48:2176-90

27 Ritter DA, Kenny JD. Influence of gestational age on cord serum bilirubin binding studies. J Pediatr 1985;106:118-21.

28 Notarianni LJ. Plasma protein binding of drugs in pregnancy and in neonates. Clin Pharmacokinet 1990;18:20-36.

29 Dixit R, Bartner LM. The jaundiced newborn: minimizing the risk. Contemporary Pediatrics 1999;16:166-83.

30 Sullivan JL. Iron, plasma antioxidants and the 'oxygen radical disease of prematurity'. Am F Dis Child 1988;142:1341-4.

31 Fink MP. On hemoglobin, hemorrhage, hypotension and nitric oxide. Crit Care Med 1998;26:991-2.

32 Yao YM, Bahrami S, Leichtfried G, Redl H, Schlag G. Significance of NO in hemorrhage-induced hemodynamic alterations, organ injury, and mortality in rats. Am F Physiol 1996; 270:H1616-23. 